\title{
Determining Certain Cardiac Electrophysiological and Biochemical Parameters Following Long-Term Exposure to Sound Pollutions in Male Rats
}

\author{
Nazemi S. ${ }^{1}$ PhD, Pejhan A. ${ }^{1}$ PhD, Azhdari-Zarmehri H. ${ }^{2}$ PhD, Mojadadi M.S.* PhD
}

*Department of Immunology, Faculty of Medicine, Sabzevar University of Medical Sciences, Sabzevar, Iran 1"Cellular and Molecular Research Center" and "Department of Physiology \& Pharmacology, Faculty of Medicine", Sabzevar University of Medical Sciences, Sabzevar, Iran

2Department of Basic Sciences, Faculty of Medical Sciences, Torbat Heydariyeh University of Medical Sciences, Torbat Heydariyeh, Iran

\begin{abstract}
Aims: Cardio-vascular diseases are of the most important health and treatment problems in the recent industrialized societies. The conducted studies show that noise and vibrations, as types of pollution, are risk factors for the cardiovascular diseases. The aim of this study was to investigate the effects of shortterm and long-term facing with noise pollution on some heart biochemical and electrophysiological parameters in the rats.

Materials \& Methods: In the experimental study, 60 male Wistar rats were randomly divided into two experimental groups including short-term (one-day facing) and long-term (30-day facing). And each one included one control group and three experimental groups (4-, 8-, and 12-hour noise facing). At last, different electrophysiological parameters of heart function were investigated via recorded electrocardiograms. The levels of creatine phosphokinase and troponin I enzymes were measured, to investigate myocardial injury. Data was analyzed by SPSS 21 software using One-way ANOVA and Tukey's post-hoc tests.

Findings: Short-term (4-hour) facing with noise pollution only led to a reduction in PR interval $(\mathrm{p}<0.05)$. Long term (8- and 12-hour) facing with noise pollution considerably reduced PR, QT, and QTc wave intervals, while increased QRS complex voltage $(\mathrm{p}<0.05)$. Short-tem (4-hour) and long-term (8 to 12hour) facing led to an increase in the heart rate $(p<0.05)$. There was no significant difference in the serum level of creatine phosphokinase and troponin I enzymes between different groups.

Conclusion: Through changes in the hemodynamic factors, continuous facing with noise pollution can increase heart rate and function in the rats.
\end{abstract}

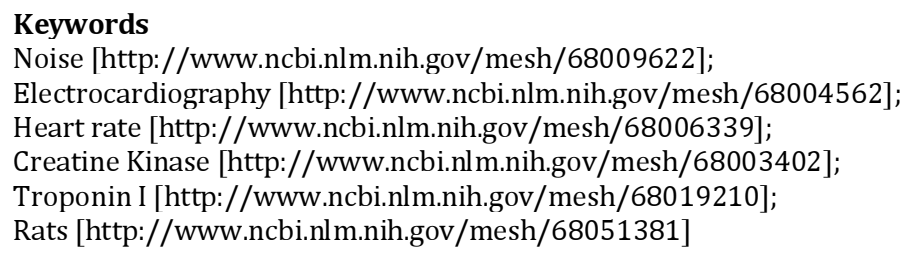

\footnotetext{
* Corresponding Author

Tel: +985144446070

Fax: +985144264462

Address: Department of Immunology, Faculty of Medicine, Building Number 2 of Sabzevar University of Medical Sciences, Kilometer 5 of Tehran Road, Sabzevar, Iran mojadadim@medsab.ac.ir 


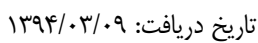

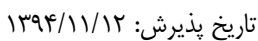
"نويسنده مسئول: mojadadim@medsab.ac.ir

\section{مقدمه}

آلودگى صوتى يكى از مهمترين معضلات زيستمحيطى جوامع

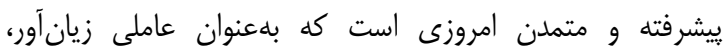
سلامتى انسانها را در معرض تهلديد قرار داده است. اثرات ناشى از

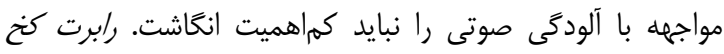

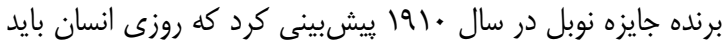

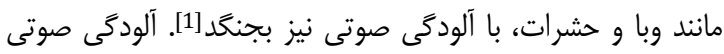

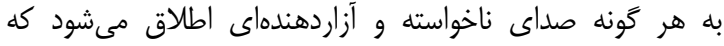
موجب ناراحتى و برهمخوردن آرامش فرد شود. مواجهه با سروصدا

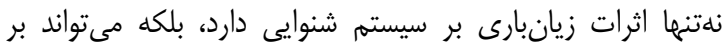

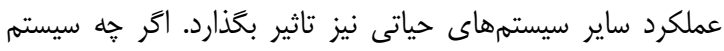

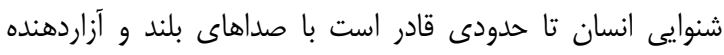

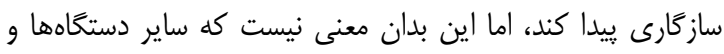

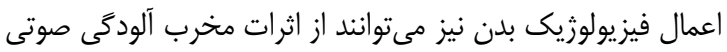

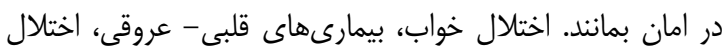

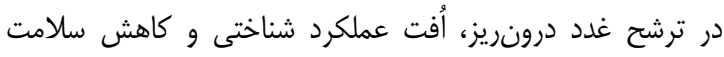
روانى از جمله مهرمترين عوارضى هستند كه تاكنون ارتباط آنها با دونيا

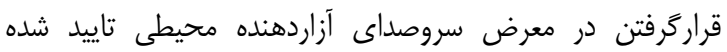

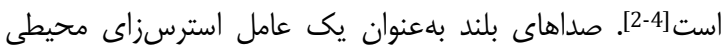

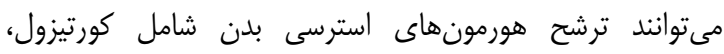

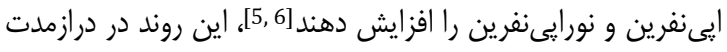
مىتواند بر عملكرد دستخاههاى مختلف بدن بهخصوص ورئ سيستم

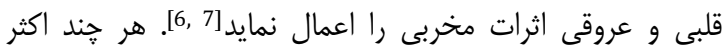
اثرات صوت موقتى هستند، اما مطالعات حيوانى نشان داده است كه كه قرارگيرى مداوم در معرض صوت موجب ايجاد يك سرى تغييرات

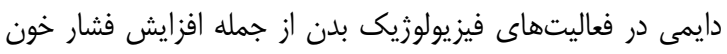
و اختلال در عملكرد سيستم قلبى - عروقى و سيستم اندوكرينى

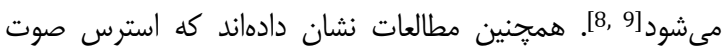
موجب ايجاد تغييرات فراساختارى در عضله قلبى موشهاى مهن

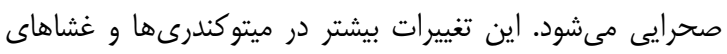

$$
\text { سار كويلاسمى بلوجود مى آيد [10,11]. }
$$

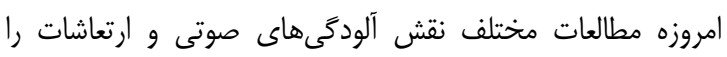
بلهنوان يك فاكتور خطرساز براى بيمارىهاى قلبى- عروقى تاييد

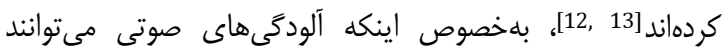
موجب بىنظمى، افزايش ضربان قلب، افزايش فشار خون، آسيب

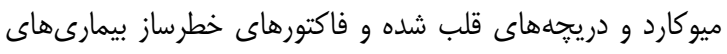

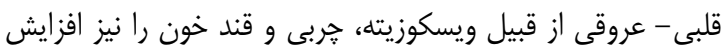
دهند[17-14]. در مطالعهاى كه ديل در فرانسه انجام شده، رابطه

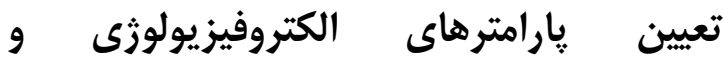

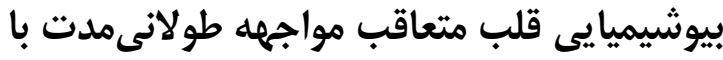
آلودَى صوتى در موشهاى صحر ايیى نر

PhD صمد ناظمى

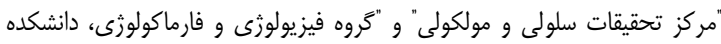

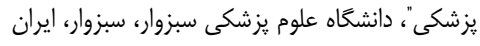

اكبر يزهان PhD

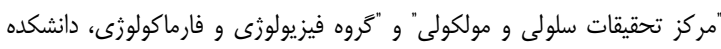
يزشكى"، دانشكاه علوم يزشكى سبزوار، سبزوار، ايران

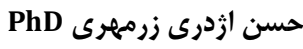

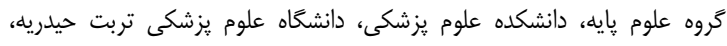
تربت حيدريه، ايران

PhD "محمدشفيع مجددى حيله، ايرنى كروه ايمونولوزى، دانشكده يزشكى، دانشَاه علوم يزشكى سبزوار، سبزوار، ايران

جكيده اهداف: بيمارىهاى قلبى - عروقى از بزرگترين معضلات بهداشتى و

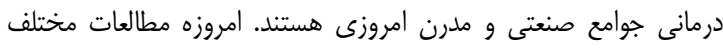

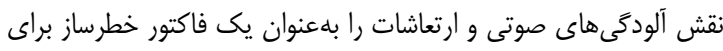

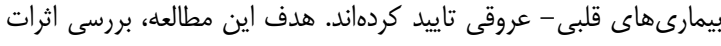

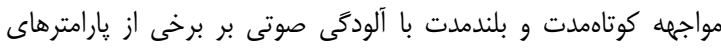

الكتروفيزيولوزى و بيوشيمايى قلب در موش صحر ائى بود. مواد و روشها: در اين آزمايش تجربى، •وسر موش صحرايى نر نزاد

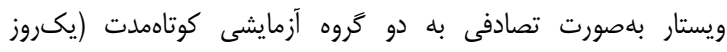

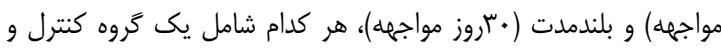

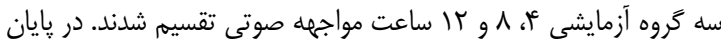

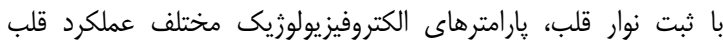

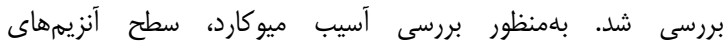

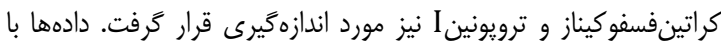

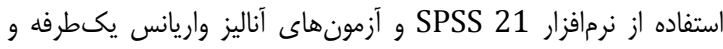
آزمون تعقيبى توكى آناليز شدند.

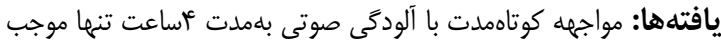

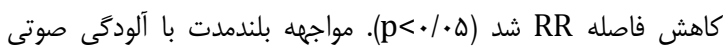

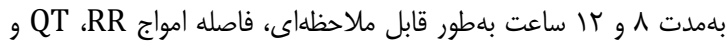

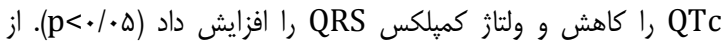

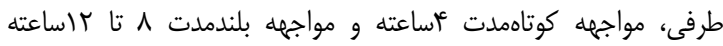

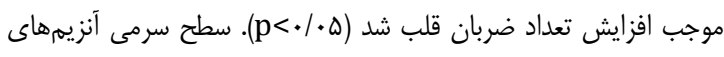

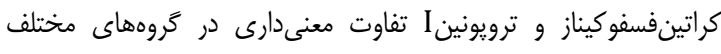
نداشت. نتيجه كَيرى: قرارگيرى مداوم در معرض آلودگى صوتى مىتواند با تغيير

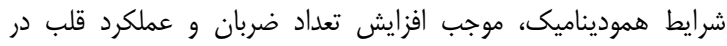
موش هاى صحر ايى شود. كليدوازه ها: آلودگى صوتى، الكتروكارديوگر افى، ضربان قلب، كراتين فسفوكيناز،

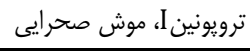




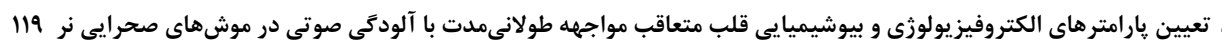

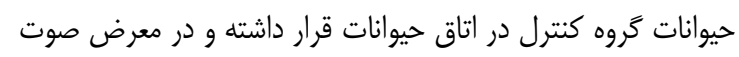

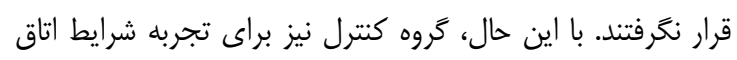

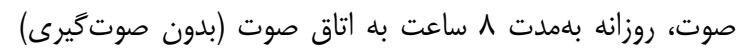

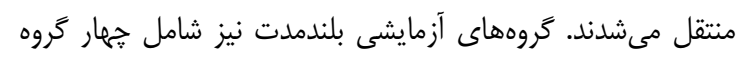

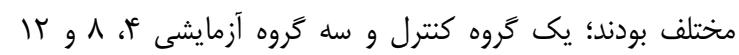

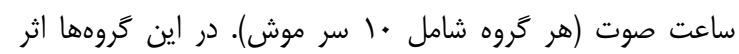

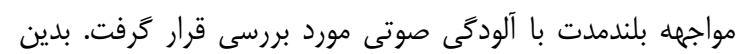

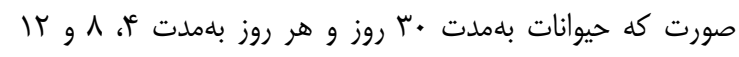

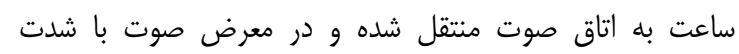

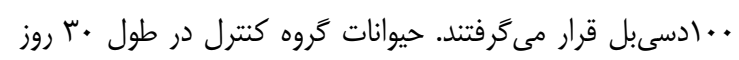

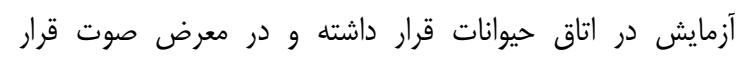

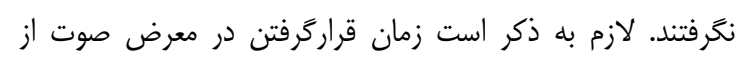

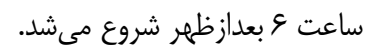
ايجاد آلودَّى صوتى: آلودگى صوتى ازئى از نوع وايتنويز با شدت

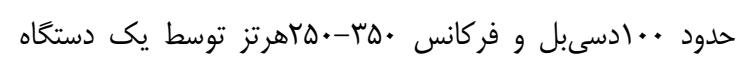

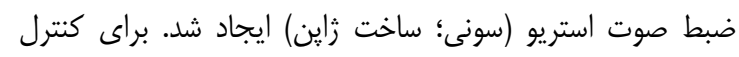

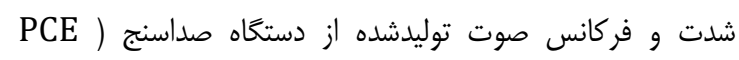
Instruments

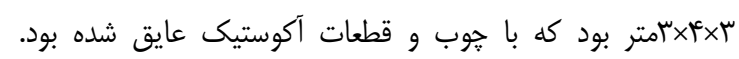

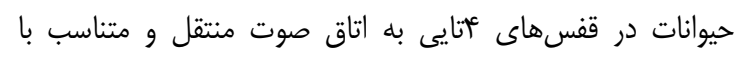

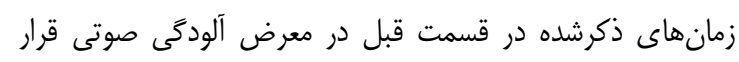

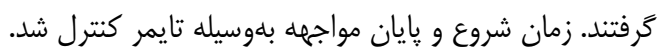

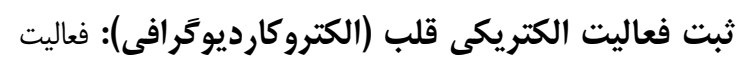

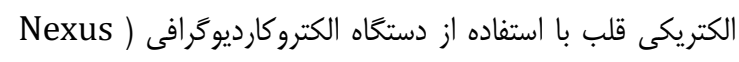

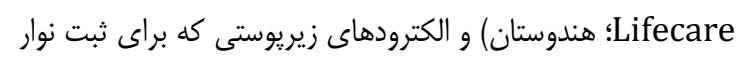

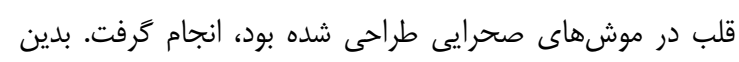

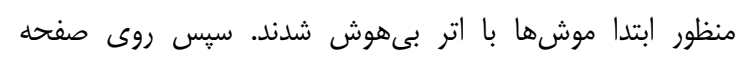

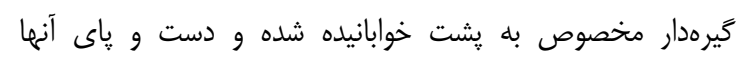

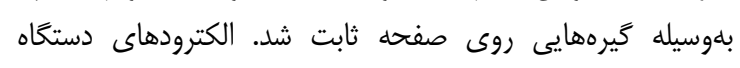

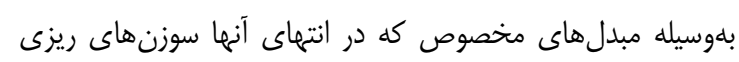

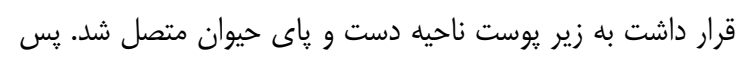

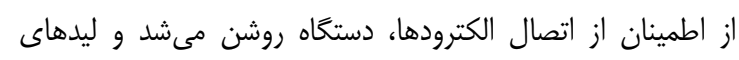

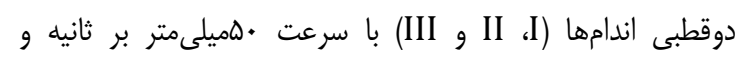

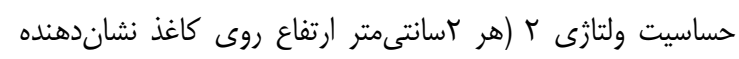

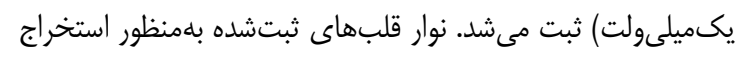

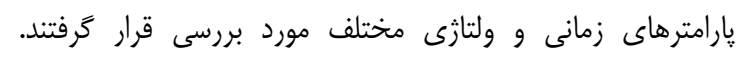

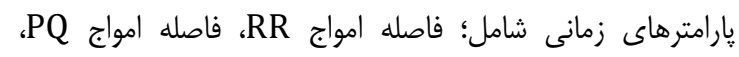

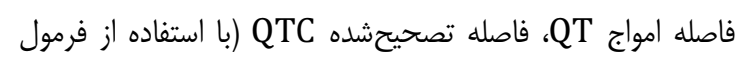

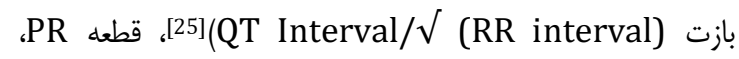

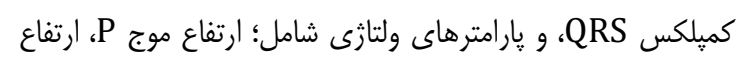

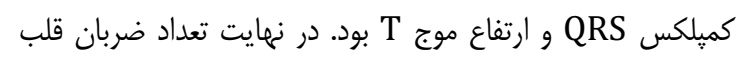
در دقيقه از روى فاصله RR در نوار قلب محاسبه شد.
معنى دارى در ميزان مركىمير ساكنان اطراف فرودكاه (قراركيرى

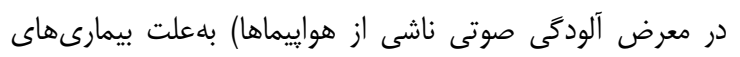

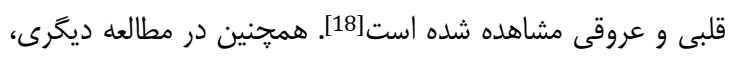

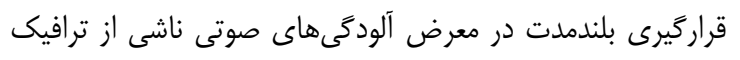

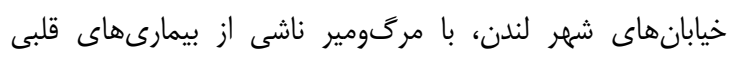
همراه بوده است [19].

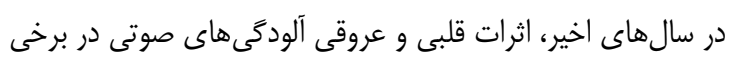

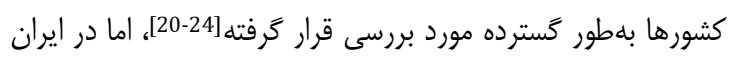

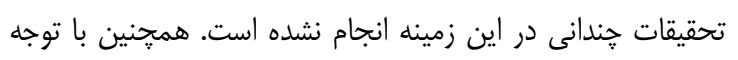

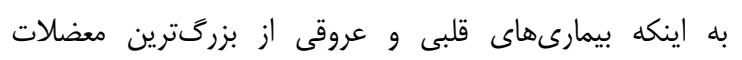

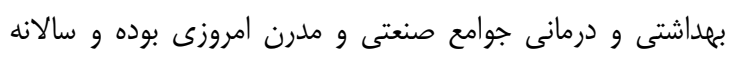

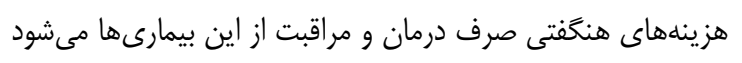

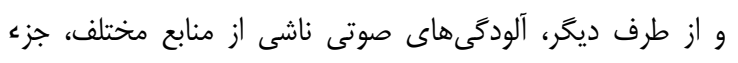

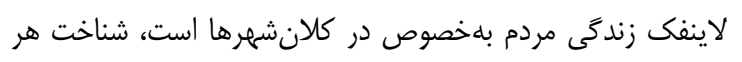

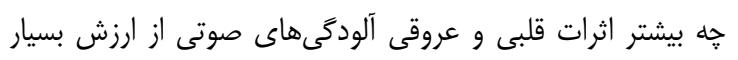
بالايى برخوردار است. از اين رو، هدف از انجام اين مطالعه بردسى اثرات الات مواجها

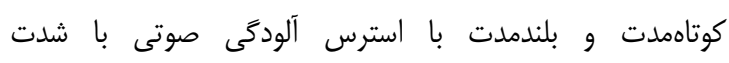

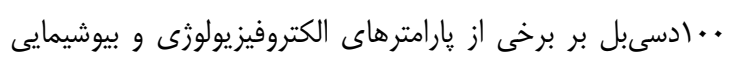

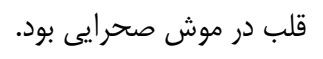

\section{مواد و روشها}

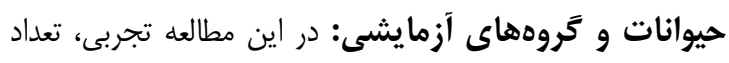

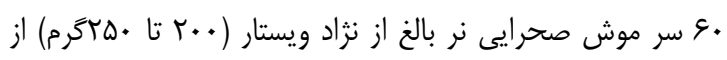

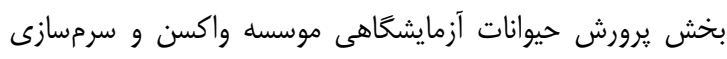

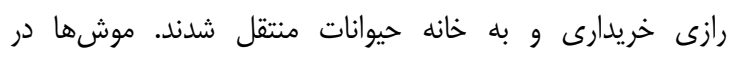

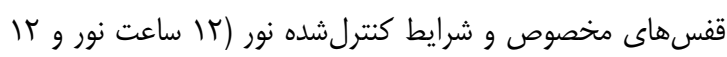

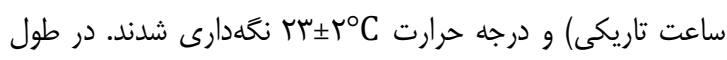

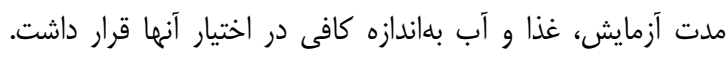

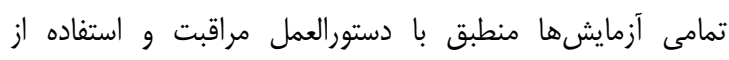

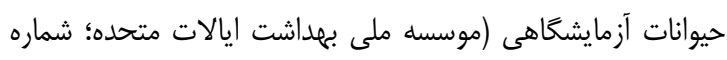

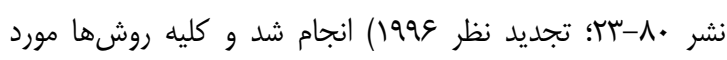

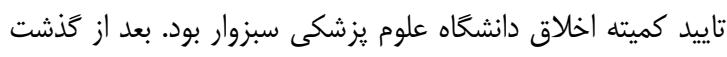

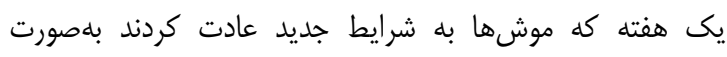

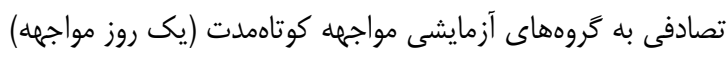

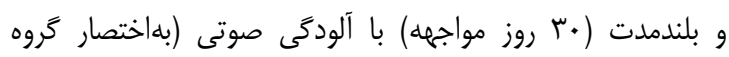

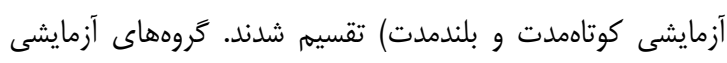

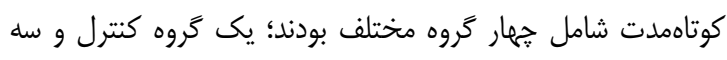

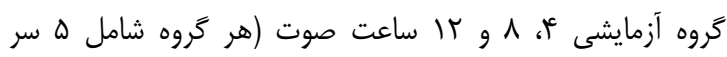

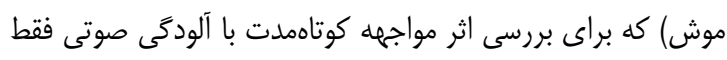

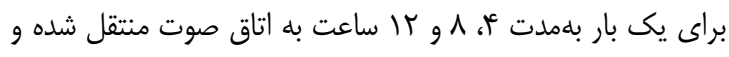

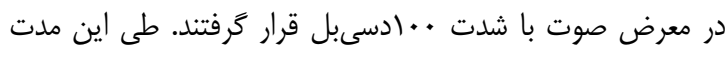




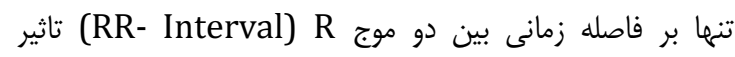

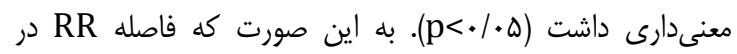

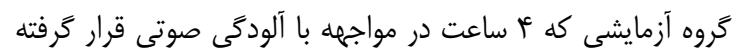

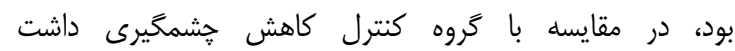

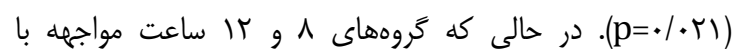

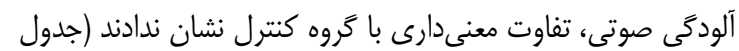

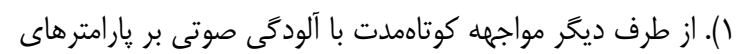

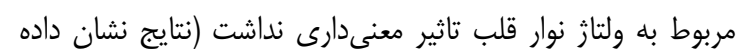

$$
\text { نشده است). }
$$

اثر مواجهه بلندمدت با آلودَّى صوتى بر يارامترهاى

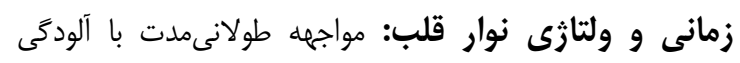

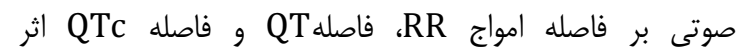

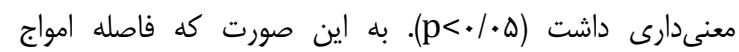

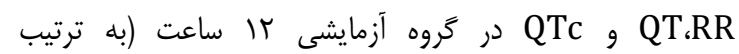
r

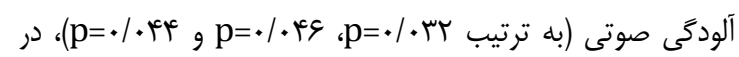

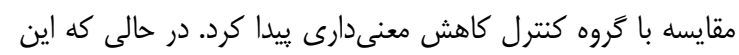

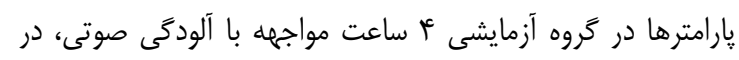

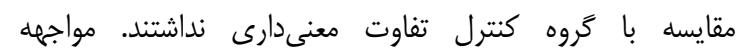

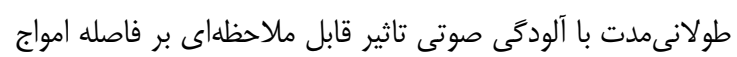

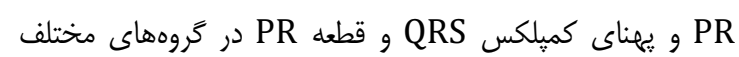

$$
\text { نداشت (ه•/. (p) جدول (1). }
$$

تعيين كيفى سطح سرمى آنزيمهاى كراتين فئنسفوكيناز

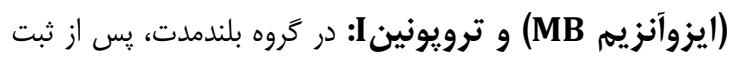

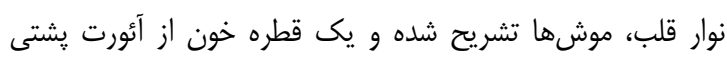

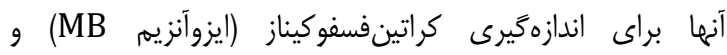

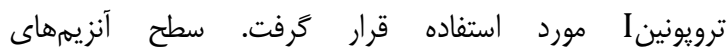

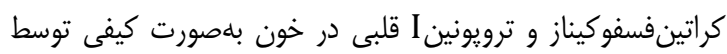

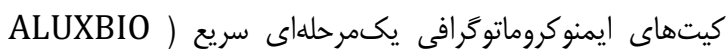
CO., LTD

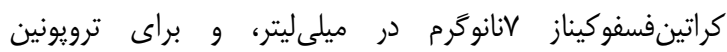

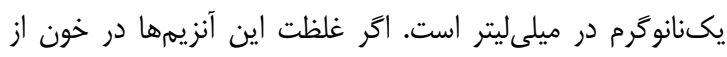

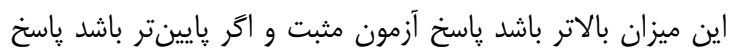

$$
\text { آزمون منفى ثبت مى شود). }
$$

تجزيه و تحليل آمارى: دادههاى بهدستآمده باديا استفاده از

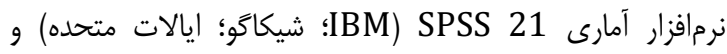

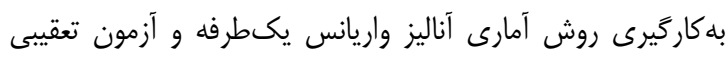

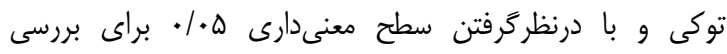

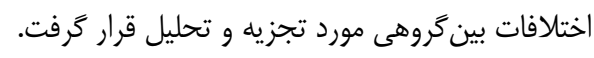

يافتهها

\begin{tabular}{|c|c|c|c|c|}
\hline זا ساعت مواجهه & ^ ساعت مواجهه & f اعت مواجهه & كنترل & شاخص \\
\hline & & & & فاصله PR (ميلىثانيه) \\
\hline D) $/ \varepsilon \cdot \pm F / W V$ & $\Delta F / \cdots \pm \Lambda / q \uparrow$ & $0 \cdot / 4 \cdot \pm \cdot / \wedge q$ & $\Delta \xi / Q Y \pm r / q)$ & كوتاهمدت \\
\hline \multirow[t]{2}{*}{$p / q 1 \pm \cdot / r q$} & $4 / 19 \pm \cdot / 4 t$ & $r / 99 \pm \cdot / V)$ & $\Delta / \cdot \Lambda \pm \cdot / R T$ & بلندمدت \\
\hline & & & \multicolumn{2}{|r|}{ كميلكس QRS (ميلىثانيه) } \\
\hline$|\varepsilon| \cdot \cdot \pm r / \cdot \cdot$ & $\mid \xi / 4 \cdot \pm f / \cdot \cdot$ & $|\varepsilon| \cdot \cdot \pm 1 / \cdot \cdot$ & $\mid Q / T \cdot \pm T / T \Lambda$ & كوتاهمدت \\
\hline \multirow[t]{2}{*}{$1 Q / D \cdot \pm T / W V$} & $\mid V / \cdot \cdot \pm r / V \cdot$ & $|\varepsilon / T \Delta \pm r / V|$ & $\mid Q / \Delta \cdot \pm \Gamma / \Delta F$ & بلندمدت \\
\hline & & & \multicolumn{2}{|r|}{ فاصله QTc (ميلىثانيه) } \\
\hline $\mid Q V / \cdot r \pm E / T \wedge$ & ه & $1 \Delta V / \cdot V \pm 19 / \Delta T$ & $\mid Q N / \cdot F \pm V / r r$ & كوتاهمدت \\
\hline \multirow[t]{2}{*}{$" r \cdot V / r \cdot \pm r \Delta / \varepsilon)$} & $" r \cdot F / T T \pm I T / \cdot \Lambda$ & $r / r / \Delta \Lambda \pm Q / \Delta T$ & $r \mu V / \mathscr{L} \cdot \pm r \Delta / r \Lambda$ & بلندمدت \\
\hline & & & \multicolumn{2}{|r|}{ فاصله QT (ميلىثانيه) } \\
\hline \multirow{3}{*}{$\begin{array}{l}\kappa \varepsilon / \cdot \cdot \pm \| \mid / \kappa . \\
\wedge \varepsilon / \cdot \cdot \pm \| 1 / / \kappa .\end{array}$} & $\Lambda T / \cdot \cdot \pm \Lambda / r \cdot$ & $\wedge \varepsilon / \cdot \cdot \pm|V / \wedge|$ & $9 T / \cdot \cdot \pm \mid r / \cdot r$ & كوتاهمدت \\
\hline & $V Q / V T \pm G / M$ & $\Lambda \cdot / \Lambda T \pm V / \cdot r$ & $9 \Delta / \cdot V \pm 1 D / \wedge f$ & بلندمدت \\
\hline & & & \multicolumn{2}{|r|}{ فاصله RR (ميلى ثانيه) } \\
\hline \multirow{3}{*}{$\begin{array}{l}\mid \Delta \varepsilon / \cdots \pm \Delta / \& \vee \\
|| r / \varepsilon \wedge \pm \mid 1 / \& \Delta\end{array}$} & $\mid \leftarrow \varepsilon / \cdots \pm \| / / 4$ & 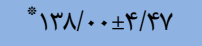 & $109 / 8 \cdot \pm 10 / \Delta$. & كوتاهمدت \\
\hline & $" \mid r V / r \cdot \pm 8 / \cdot V$ & $|f| / v \cdot \pm \mid r / \cdot q$ & $10 q / V \cdot \pm r \cdot / F^{2} \Lambda$ & بلندمدت \\
\hline & & & \multicolumn{2}{|r|}{ قطعه PR (ميلى ثانيه) } \\
\hline \multirow{2}{*}{$\begin{array}{l}r V / A r \pm V / q . \\
r r / V \Delta \pm q / \mathcal{}\end{array}$} & $r \varepsilon / \pi f \pm \varepsilon / q$. & $r q / 4 \cdot \pm \cdot / 1 q$ & $r \Delta / \kappa \varphi \pm \varepsilon / \Lambda \mu$ & كوتاهمدت \\
\hline & $r \cdot|\varepsilon \Delta \pm \varepsilon| . \cdot$ & $r q / \Delta \Delta \pm \varepsilon / F)$ & $r r / q \cdot \pm \Delta / F i$ & بلندمدت \\
\hline
\end{tabular}
اثر مواجهه كوتاهمدت با آلودَّى صوتى بر يارامترهاي

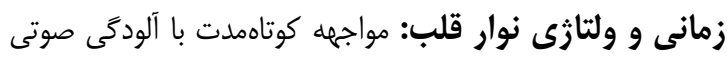

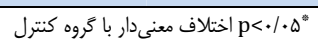




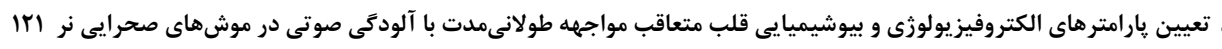

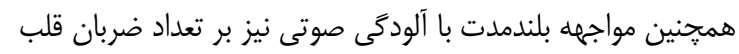

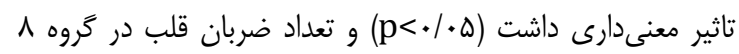
ساعت (اس (•/

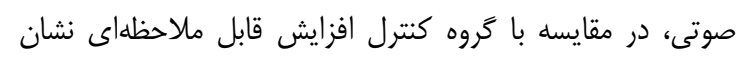

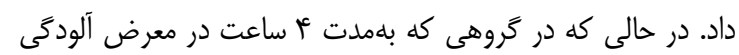

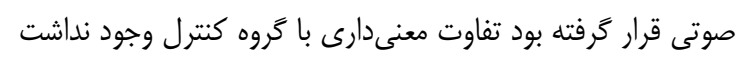

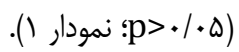

اثر مواجهه بلندمدت با آلودَى صوتى بر سطح آنزيمهاى كراتينفسفوكيناز (CPK) و ترويونين I إنبى (TnI)

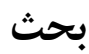

نتايج حاصل از اين مطالعه نشان داد كه مواجهه كوتاهمدت و

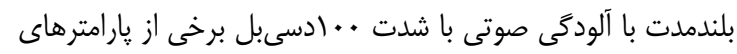

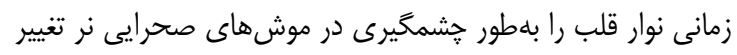

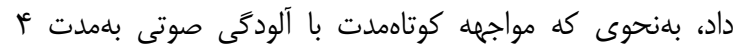
ساعت موجب كاهش فاصله امواج RR شد، در حالى كه مواجهيه

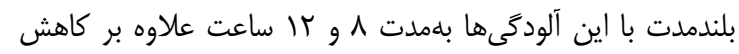

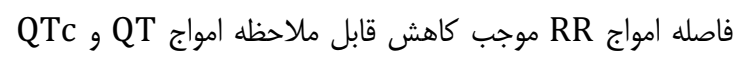
نيز شد. همجنين مواجهه طولانىمدت با آلودگى صوتى موجى موجب

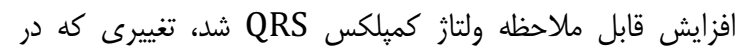

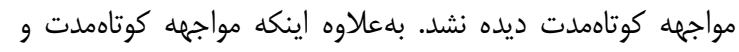

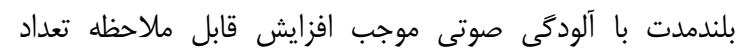
ضربان قلب در موشهاى صحرايى شد. با اين تفاوت كه در

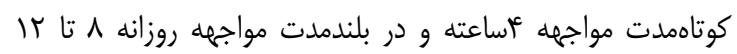
ساعت با آلودگى صوتى موجب افزايش تعداد ضربان قلب شد.

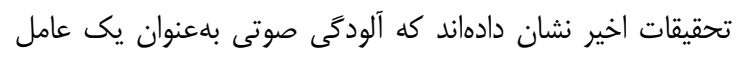

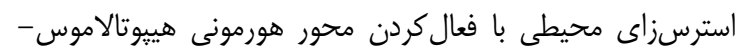

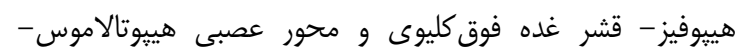

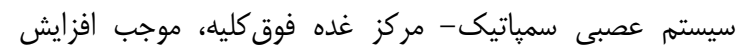

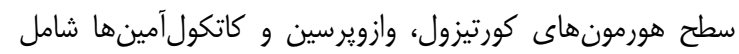
ايىنفرين و نورايىنفرين در خون شده و و يك سرى سئ تغييرات

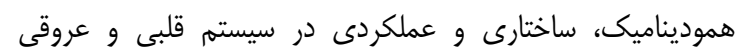

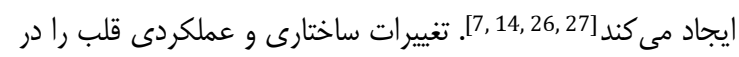
اين شرايط مىتوان تا حدودى با استفاده از يارامترهاى مختلف نوار

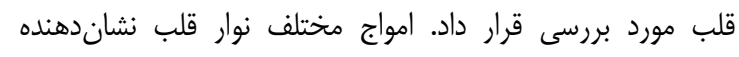
وقايعى است كه در يك دوره كامل قلبى (سيستول و دياستول)

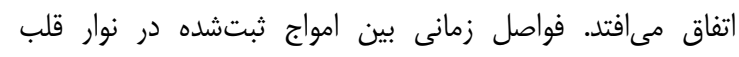

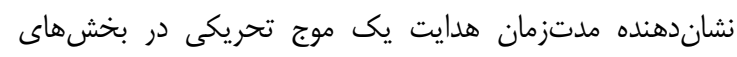
مختلف قلب است. با افزايش تخليه سيستم سمياتيكى، سرعت مدان

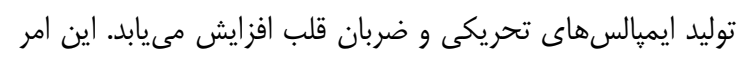
موجب كاهش فواصل زمانى بين امواج مختلف نوار قلب از جمله

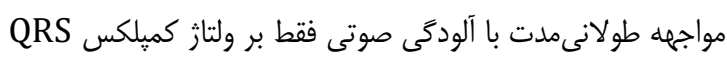

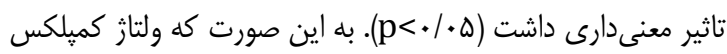

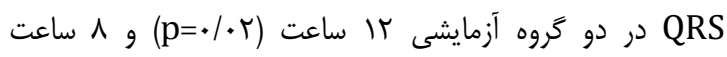

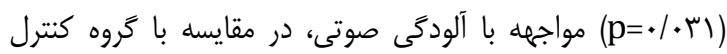

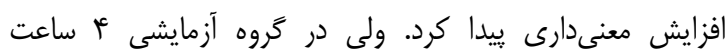

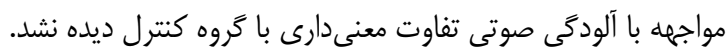

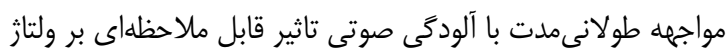

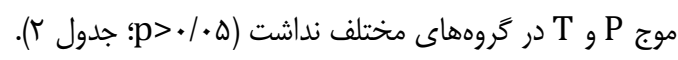

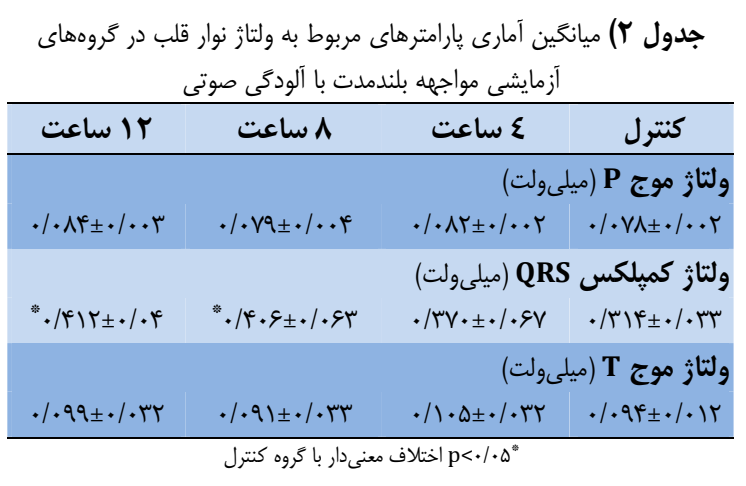

اثر مواجهه كوتاهمدت و بلندمدت با آلودَّى صوتى بر

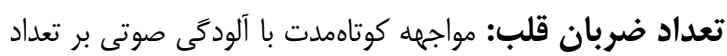

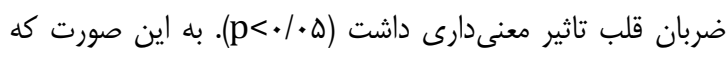

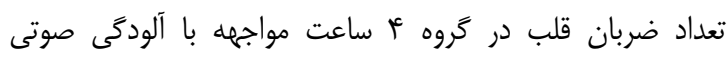
افزايش قابل ملاحظهاى در مقايسه با گروه كنترل

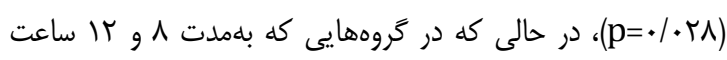

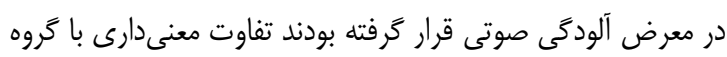
كنترل مشاهده نشد (نمودار ()).

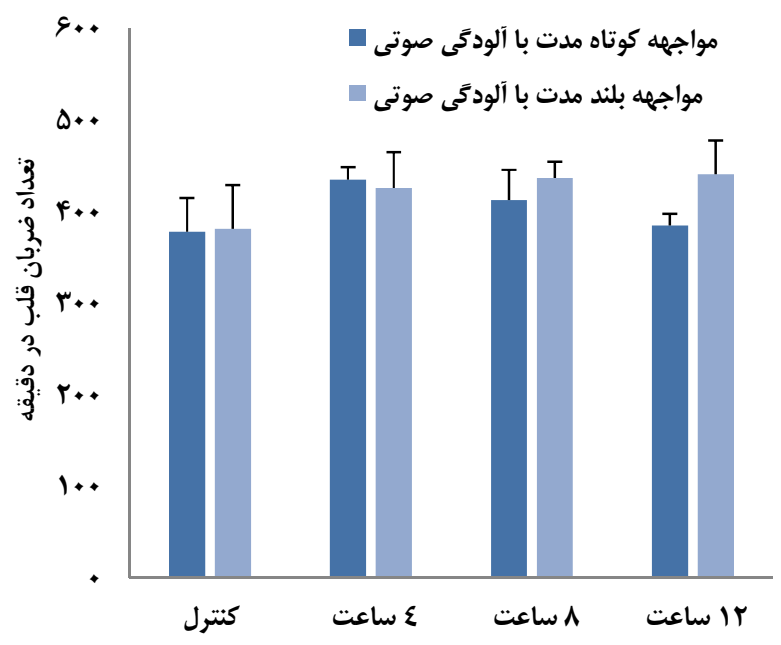

نمودار () تعداد ضربان قلب در دقيقه، در گروههاى آزمايشى مواجها كوتاهمدت

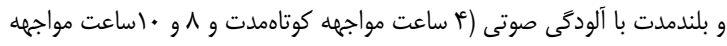
بلندمدت در سطح هـ / • با كروه كنترل اختلاف معنى دار داشتند) 


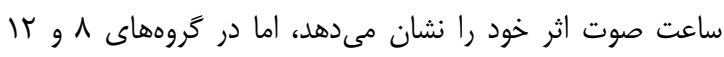
ساعت صوت بلهعلت خستهشدن سيسته سمياتيك اثر تحريكى آن بر افزايش ضربان قلب كاهش مىيابد. از سوى ديخر مشخص شده كه استرسهاى صوتى در درازمدت، ميزان عصبدهى سمياتيكى

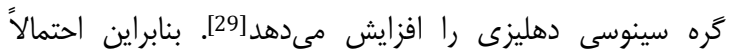

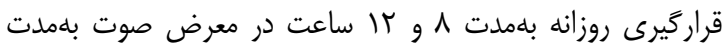
•r روز با ايجاد تغييراتى در ميزان عصبدهى سمياتيكى قلب رولب بهخصوص در گره سينوسى دهليزى، يا افزايش قدرت توليد ايىنفرين و نورايىنفرين در نورونهاى سمياتيكى، موجب تقويت اثر برهي تحريكى سيستم سمياتيك بر قلب مى شود.

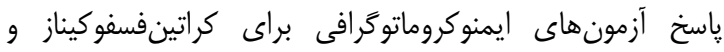

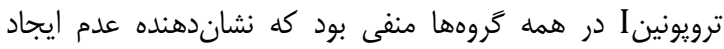
آسيب شديد در عضله قلبى است. در بسيارى از تحقيقات نشان داده

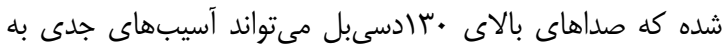
سلولهاى ميوكارد وارد كند و حتى منجر بله سكته قلبى نيز

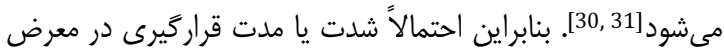
صوت كه در اين تحقيق مورد استفاده قرار گرفته، براى ايجاد هنين صدماتى كافى نبوده است. از محدوديتهاى اين مطالعه مىتوان به مشكلبودن ارايه تعريف

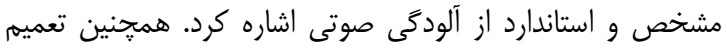

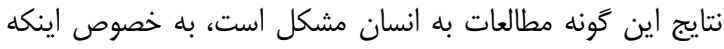

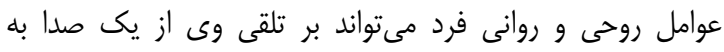
عنوان آلودگى و همجنين اثرات مخرب آن آن تاثير داشته باشد. لذا

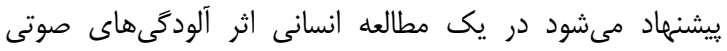

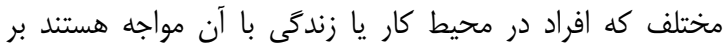

وضعيت عملكرد سيستم قلب و عروق مورد بررسى قرار كيرد.

\section{نتيجه كيرى}

مواجهه كوتاهمدت با آلودگى صوتى با شدت .. ادسىبل مىتواند

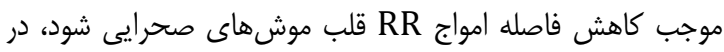
حالى كه مواجها بلندمدت با آلودگى صوتى، علاوه بر كاهش فاصل فاصله

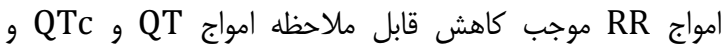

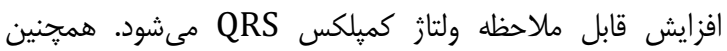

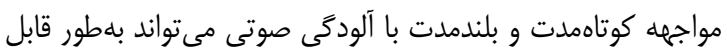
ملاحظهاى سبب افزايش تعداد ضربان قلب در موشهاى صحاى صحرايى

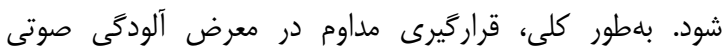
مىتواند با تغيير شرايط هموديناميك موجب افزايش تعداد ضربان و عملكرد قلب شود.

تشكر و قدردانى: بدين وسيله از معاونت تحقيقات و فناورى دانشگاه علوم يزشكى سبزوار تشكر و قدردانى مى شودد.

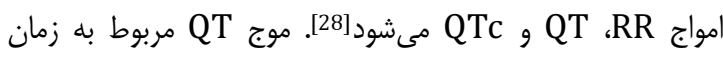

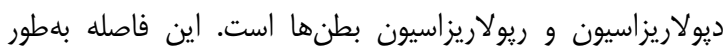

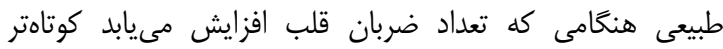

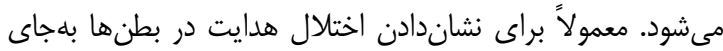
فاصله QT از فاصله تصحيحشده QT استفاده مى فيود، كه در اين مطالعه كاهش معنى دارى را در مقايسه با كروه كنترل نشان دادند.

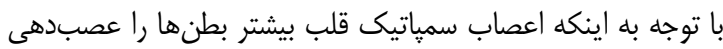

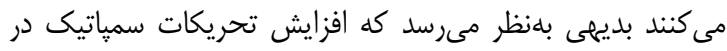

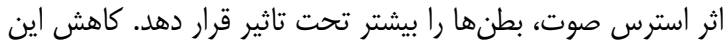

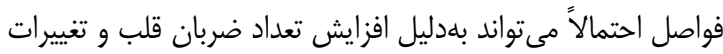
ساختارى ايجادشده در قلب و سيستم هدايت داخل بطنى در ياسخ

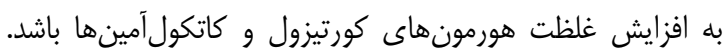

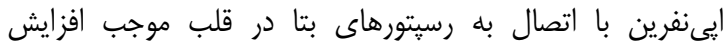

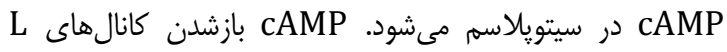
كلسيمى را آسانتر كرده و ورود كلسيم را به داخل سلول كالول افزايش

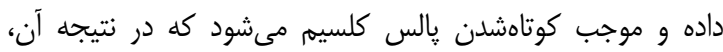

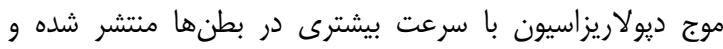

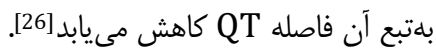
كميلكس QRS حاصل ديولاريزاسيون بطنها است. افزايش ولتاز

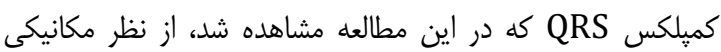
مىتواند بهمنزله انقباض شديدتر بطنها يا افزايش توده عضلانى إنى

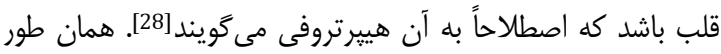
كه اشاره شد، استرسهاى صوتى مىتوانند موجب افزايش

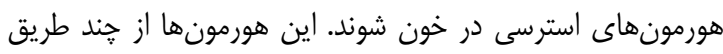

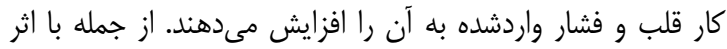

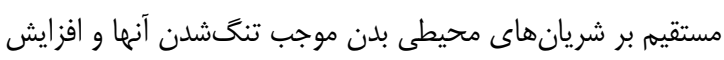

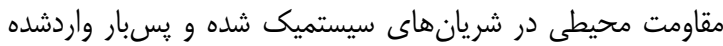

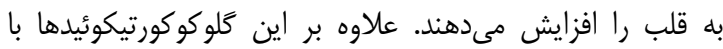
فعال كردن مسير رنين - آنزيوتانسين - آلدوسترون موجب افزئ إنايش

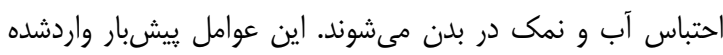

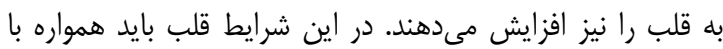

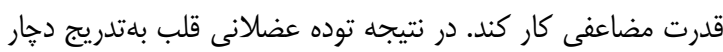

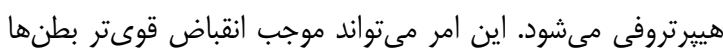

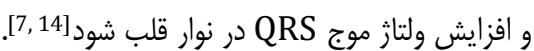

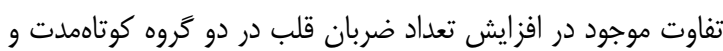

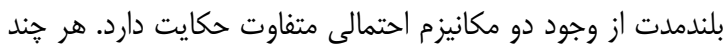

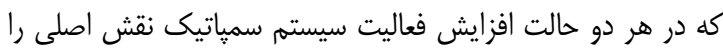

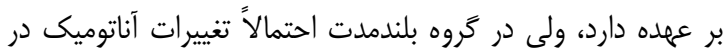

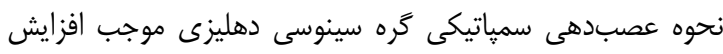

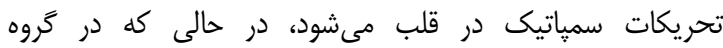

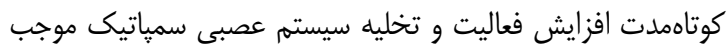

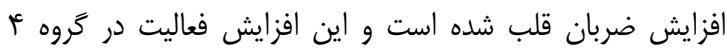




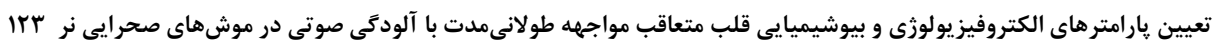

14- Babisch W. Cardiovascular effects of noise. Noise Health. 2011;13(52):201-4.

15- McClintock PV, Stefanovska A. Noise and determinism in cardiovascular dynamics. Phys Stat Mech Appl. 2002;314(1-4):69-76.

16- Takeuchi H, Enzo A, Minamitani H. Circadian rhythm changes in heart rate variability during chronic sound stress. Med Biol Eng Comput. 2001;39(1):113-7.

17- Ismaila SO, Odusote A. Noise exposure as a factor in the increase of blood pressure of workers in a sack manufacturing industry. Beni-Suef Univ J Basic Appl Sci. 2014;3(2):116-21.

18- Evrard AS, Bouaoun L, Champelovier P, Lambert J, Laumon B. Does exposure to aircraft noise increase the mortality from cardiovascular disease in the population living in the vicinity of airports? Results of an ecological study in France. Noise Health. 2015;17(78):328-36.

19- Stansfeld S, Crombie R. Cardiovascular effects of environmental noise: Research in the United Kingdom. Noise Health. 2011;13(52):229-33.

20- Lercher P, Botteldooren D, Widmann U, Uhrner U, Kammeringer E. Cardiovascular effects of environmental noise: research in Austria. Noise Health. 2011;13(52):234-50.

21- Kempen E. Cardiovascular effects of environmental noise: research in The Netherlands. Noise Health. 2011;13(52):221-8.

22- Belojevic G, Paunovic K, Jakovljevic B, Stojanov V, Ilic J, Slepcevic V, et al. Cardiovascular effects of environmental noise: research in Serbia. Noise Health. 2011;13(52):217-20.

23- Bluhm G, Eriksson C. Cardiovascular effects of environmental noise: Research in Sweden. Noise Health. 2011;13(52):212-6.

24- Maschke C. Cardiovascular effects of environmental noise: research in Germany. Noise Health. 2011;13(52):205-11.

25- Ahnve S. Correction of the QT interval for heart rate: Review of different formulas and the use of Bazett's formula in myocardial infarction. Am Heart J. 1985;109(3 Pt 1):568-74.

26- Babisch W, Fromme H, Beyer A, Ising H. Increased catecholamine levels in urine in subjects exposed to road traffic noise: the role of stress hormones in noise research. Environ Int. 2001;26(7-8):475-81.

27- Spreng $M$. Central nervous system activation by noise. Noise Health. 2000;2(7):49-58.

28- Bacharova L, Kyselovic J, Klimas J. QRS voltageduration product in the identification of left ventricular hypertrophy in spontaneously hypertensive rats. Arq Bras Cardiol. 2002;79(2):143-8.

29- Paparelli A, Soldani P, Breschi M, Martinotti E, Scatizzi R, Berrettini S, et al. Effects of subacute exposure to noise on the noradrenergic innervation of the cardiovascular system in young and aged rats: a morphofunctional study. J Neural Transm Gen Sect. 1992;88(2):105-13.

30- Sorensen M, Andersen ZJ, Nordsborg RB, Jensen SS, Lillelund KG, Beelen $R$, et al. Road traffic noise and incident myocardial infarction: a prospective cohort study. PLoS One. 2012;7(6):e39283.

31- Munzel T, Gori T, Babisch W, Basner M. Cardiovascular effects of environmental noise exposure. Eur Heart J. 2014;35(13):829-36.

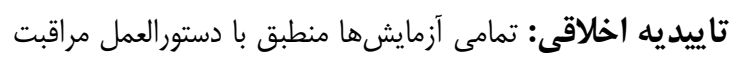

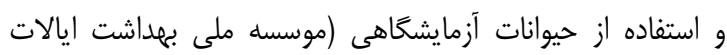

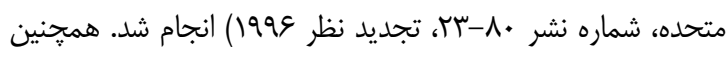

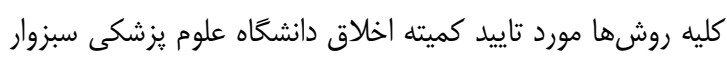

$$
\begin{aligned}
& \text { تود. - مارض } \\
& \text { تعارض منافع: هيج كَنه تعارض منافع توسط نويسندكان بيان } \\
& \text { نشده است. } \\
& \text { منابع مالى: اين طرح با حمايت مالى معاونت تحقيقات و فناورى } \\
& \text { دانشگاه علوم يزشكى سبزوار انجام شده است. }
\end{aligned}
$$

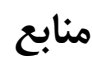

1- Basner M, Babisch W, Davis A, Brink M, Clark C, Janssen $S$, et al. Auditory and non-auditory effects of noise on health. Lancet. 2014;383(9925):1325-32.

2- Saremi M, Rezapour R. Non-auditory Effects Caused by Environmental Noise Pollution. J Kerman Univ Med Sci. 2013;20(3):312-25. [Persian]

3- van Kempen E, Babisch W. The quantitative relationship between road traffic noise and hypertension: a meta-analysis. J Hypertens. 2012;30(6):1075-86.

4- Stansfeld SA, Matheson MP. Noise pollution: nonauditory effects on health. Br Med Bull. 2003;68:243-57.

5 - Brouček J. Effect of noise on performance, stress, and behaviour of animals. Stovak J Anim Sci. 2014;47(2):11123.

6- Ising H, Braun C. Acute and chronic endocrine effects of noise: review of the research conducted at the Institute for Water, Soil and Air Hygiene. Noise Health. 2000;2(7):7-24.

7- Babisch W. Stress hormones in the research on cardiovascular effects of noise. Noise Health. 2003;5(18):1-11.

8- Nazemi S, Pejhan A, Azhdari-Zarmehri H, Mojadadi MS. The effects of sound pollution on the serum levels of corticosterone and other hematological parameters in male rats. J Babol Univ Med Sci. 2015;17(8):41-7. [Persian]

9- de Souza TC, Périssé AR, Moura M. Noise exposure and hypertension: Investigation of a silent relationship. Bio Med Central. 2015;15:328.

10- Gesi M, Riva A, Soldani P, Fornai F, Natale G, Lenzi P, et al. Central and peripheral benzodiazepine ligands prevent mitochondrial damage induced by noise exposure in the rat myocardium: an ultrastructural study. Anat Rec. 1999;255(3):334-41.

11- Rahma MS, Win NN, Rafidah HM, Kamal T, Ailin R. The effects of noise on cardiovascular parameters using isolated rats hearts. Sci Ser Data Rep. 2012;4(12):39-50.

12- Babisch W, Beule B, Schust M, Kersten N, Ising H. Traffic noise and risk of myocardial infarction. Epidemiol. 2005;16(1):33-40.

13- Selander J, Nilsson ME, Bluhm G, Rosenlund M, Lindqvist $M$, Nise $G$, et al. Long-term exposure to road traffic noise and myocardial infarction. Epidemiol. 2009;20(2):272-9. 